\title{
COMPARISION OF DOMINANT FEATURES IDENTIFICATION FOR TOOL WEAR IN HARD TURNING OF INCONEL 718 BY USING VIBRATION ANALYSIS
}

\author{
DASARI Kondala Rao' ${ }^{1}$, KOLLA Srinivas ${ }^{2}$ \\ ${ }^{1}$ Research scholar, Dept. of Mechanical Engg, University college of engineering \& Technology, Acharya \\ Nagarjuna University, Guntur, Andhra Pradesh, India.e-mail: kondalmech@gmail.com \\ ${ }^{2}$ Professor, Dept. of Mechanical Engg., R.V.R. \& J.C. College of Engineering, Guntur, \\ Andhra Pradesh, India, e-mail: dr.kollasrinivas@gmail.com
}

\begin{abstract}
In various machining processes, the vibration signals are studied for tool condition monitoring often referred as wear monitoring. It is essential to overcome unpredicted machining trouble and to improvise the efficiency of the machine. Tool wear is a vital problem in materials such as nickel based alloys as they have high hardness ranges. Though they have high hardness, a nickel based alloy Inconel 718 with varying HRC (51, 53, and 55), is opted as work material for hard turning process in this work. Uncoated carbide, coated carbide and ceramic tools are employed as cutting tools. Taguchi's L9 orthogonal array is considered by taking hardness, speed, feed and depth of cut as four input parameters, the number of experiments and the combinations of parameters for every run is obtained. The vibration signals are recorded at various stages of cutting, till the tool failure is observed. Taking this vibration signal data as input to ANOVA and Grey relation analysis (GRA) which categorizes the optimal and utmost dominant features such as Root Mean Square (RMS), Crest Factor (CF), Skewness (Sk), Kurtosis (Ku), Absolute Deviation (AD), Mean, Standard Deviation (SD), Variance, peak, Frequency and Time in the tool wear process.
\end{abstract}

KEYWORDS: Hard turning, Tool condition Monitoring, Dominant features, Vibration signals, GRA, ANOVA.

\section{Introduction}

In aerospace applications Nickel-based super alloys are widely used due to their magnificent corrosion resistance and mechanical properties maintained at high temperature. Especially Machining of Ni based alloys is still a challenge in dry machining. Super alloys characteristics like high temperature, tensile strength, shear strength, strain hardening, decrease in thermal conductivity, built up edge formation and the occurrence of abrasive particles in their microstructures etc. are induce high thermo-mechanical loads at the tool-chip interface resulting in important wear of the tool [1]. Cemented carbide inserts were not suitable to machine $\mathrm{Ni}$ based alloys at high speed since they cannot survive the conditions of acute high temperature and stress in the cutting zone. In general, the suggested range of cutting speeds up to $30 \mathrm{~m} / \mathrm{min}$ for uncoated tools and up to $100 \mathrm{~m} / \mathrm{min}$ when machining Ni-based alloys using cemented carbide inserts properly coated [2]. Ceramic tools have been used gradually more

In metal-cutting processes tool wear is a complex phenomenon occurring in various ways. Normally, the surface finish is mainly affected by a worn tool and therefore there is a necessity to build up tool condition monitoring (TCM) systems that alert the machinist to the tool wear state, thereby avoiding adverse effects [3]. TCM systems that were improved in the past are comprehensively reviewed in a number of articles.

A good quality cutting TCM system [4] should be characterized by (i) gradual tool wear (crater and flank) caused by abrasion due to friction between cutting tool and work piece (flank wear) and cutting tool and chip (crater wear), (ii)tool chipping (cutting edge breakage) and (iii) 
fast recognition of impact or collisions, (i.e., unwanted movement between tool and work piece) Tool wear sensing methods are generally classified into two types: direct and indirect tool wear monitoring methods The direct methods can be applied when cutting tools are not in contact with the work piece [5] like radioactive, microscope, camera vision and so on. These indirect methods can be developed to an industrial problem, but they have a lower sensitivity compared to direct methods However, a problem in TCM system is selection of proper sensor and its location. The sensors have to be placed as close to the tool tip being monitored. It is exciting to note that an indirect TCM system [6] consists of four steps: (i) collection of data in signals from sensors such as cutting force, vibration, temperature, acoustic emission and/or motor current, (ii) features extraction from the signals, (iii)tool wear estimation using pattern recognition, fuzzy logic, neural networks, or regression analysis, and (iv) implement of an adaptive system to control the machining process based on data from the sensors[7,8]. The present work is going to be use vibration indirect method.

\subsection{Vibration Signature:}

vibrations happen as a result of rubbing action between the work piece and chip against the tool in turning operation. If the tool wear increases, variation will be observed in tool signature provided by these vibrations. The vibration free cutting processes greatly effects the operation of machine tool in terms of its performance. The increase of deterioration rate and inaccuracies with respect to time can be certainly measured by vibration monitoring in a machine tool. In general, these vibration signals can be recorded by means of a sensing device named accelerometer. These vibration monitoring techniques [9,11-16] are reviewed by the researchers Dan and Mathew [10] as more economical, efficient and practical, also stated the merits and demerits. Teti et al. [17] also described various vibration sensing techniques [18,19] to monitor flank wear in their full comprehensive survey conducted on machine monitoring techniques. Rajesh and Narayanan Namboothiri [20] conducted nonlinear time series analysis by examining the vibration signals which are occurred all through the cutting process. Ding and $\mathrm{He}$ [21] also researched on tool condition monitoring information attained from cutting tool vibration signals, Acoustic Emission signals, servo motor current signals, spindle and microscopy technique, based on which they developed a model among tool wear states and reliability. The developed model provides more effective assessment for tool reliability. Quantifying the vibration signal is easy but the recorded signals are significantly dependent on all the cutting conditions, material of the work piece and machine structure.

\section{Methodology}

The proposed methods were tested using a single point cutting tool in an industrial highspeed turning lathe machine Lokesh TL200. Vibration measurements are noted over a period using vibration sensor. During the measuring period, the tool is periodically removed from the chuck, and tool wear is measured using 'Tool Makers microscope'. This produced a baseline time plot of actual tool wear versus time. Eleven features, generally used for machinery monitoring in industries, are calculated from the measured vibration data. ANOVA was applied to observe the most contributing feature among the eleven features. The GRA method was then used to observe the optimal feature values with the help of Artificial Neural network (ANN).

\section{Experimental work}

\subsection{Work material, Tools and measurement of flak wear}

The present work is completed on CNC lathe Lokesh TL250. All the turning operations are conducted on a round bar (50 mm dia and 10kg weight) of Inconel 718, hardness (51,53 and 55HRC) with uncoated cemented carbide insert (TNMG160408 MS SW05), coated cemented 
carbide insert (TNMG160408 MS PR1305) and ceramic tool (TNMG160408 A65) with tool holder MTJNL 2020K16 without cutting fluid for this investigation.

The flank wear of three tool inserts is determined using Tool maker's microscope (LT-24) by Elshaddai Engineering Equipment's. The specifications of the microscope include a Magnification of $30 \mathrm{X}$ with X-Y movement on ball bearing slides, $25 \mathrm{~mm}$ graduated micrometers and least count of $0.001 \mathrm{~mm}$. In this work, for every $120 \mathrm{~mm}$ length of cut the tool flank wear is measured for each workpiece.

\subsection{Cutting conditions}

The present work focusses on the comparison of extracted dominant features of flank wear with uncoated coated and ceramic inserts with dry machining. Experiments are conducted taking four cutting parameters (speed, feed rate, depth of cut and hardness) into account with three levels for every parameter. The details are clearly mentioned in the Table1.

Table.1 Experimental Factors and their levels
\begin{tabular}{|c|c|c|c|c|}
\hline $\begin{array}{l}\text { Levels of } \\
\text { the } \\
\text { experimental } \\
\text { factors }\end{array}$ & $\begin{array}{l}\text { Factors } \\
\text { Speed, } \\
\mathrm{N}(\mathrm{rpm})\end{array}$ & $\begin{array}{l}\text { Feed rate, } \\
\mathrm{f} \\
(\mathrm{mm} / \mathrm{rev})\end{array}$ & $\begin{array}{l}\text { Depth of } \\
\text { cut, } \mathrm{d} \\
(\mathrm{mm})\end{array}$ & $\begin{array}{l}\text { Hardness } \\
(\text { HRC })\end{array}$ \\
\hline 1 & 50 & 0.05 & 0.15 & 51 \\
\hline 2 & 65 & 0.075 & 0.2 & 53 \\
\hline 3 & 80 & 0.1 & 0.25 & 55 \\
\hline
\end{tabular}

\subsection{Measurement and processing of cutting vibration signals}

By means of Taguchi's L9 orthogonal array the number of experiments and the combinations of parameters for every run is obtained. The vibration signals are recorded at different stages of cutting, till the tool failure is observed.

The vibration signals were measured using a Kistler8704B100M1uni-axial accelerometer have been mounted on top of the tool holder with magnetic clamp (Kistler 8443B), and placed possibly near to the tool insert. The frequency range of accelerometer is $1 \mathrm{~Hz}$ to $10 \mathrm{kHz}$ and the sensitivity of the accelerometer is $50 \mathrm{mV} / \mathrm{g}( \pm 5 \%)$ The accelerometer detected the vibration signals in z-direction. In the end the trained signal is directed to laptop with LabVIEW software in order to display and storage. The vibration signal data is collected and stored in an excel file, can be processed and analyzed later.

\section{Results and discussion}

The nine experimental runs were performed based on the combinations from Table 1 with each experimental run carried for a length of $120 \mathrm{~mm}$. All the operations on CNC were performed using numerical control part programming. By using high resolution Tool maker's microscope, the tool flank wear is measured. The tool wear obtained from tool maker's microscope were given in the table 2 . The uncoated carbide cutting tool vibration signals of Fig. 1 have been captured for all the combinations cited in Table 1 (similarly coated carbide tool signals also captured) cutting speed, feed, depth of cut and hardness of the material.

Various Features were calculated by using Lab View software and MATLAB for each and every signals collected by accelerometer. These features and corresponding outputs (tool wear, surface roughness and temperature) trained with Neural Network by considering the parameters and got high accuracy of $98 \%$. After obtaining satisfactory relation between features and outputs in neural network training, we simulated the results for different variations in the features and obtained the outputs which was presented in the following figures 2 to 10 .

\subsection{Grey relation Analysis for Vibration}


The average grey relational grade of each factor at each level was obtained by taking the average of the grey relational grades for the required factor at the required level. The best level for each factor was obtained based on 'higher is better' characteristic. The trend of grey relational grade of the experimental runs was graphically represented in Fig. 11. The dominant feature was attained by taking the extreme value of all factors. Fig.12 shows the sequence of dominant features. AD is the manipulating feature of tool wear for two tool inserts and values are maximum for coated carbide tool insert, minimum for uncoated carbide tool insert.

Table.2 Manual Tool Wear for uncoated, coated and ceramic tool inserts from Tool maker's microscope

\begin{tabular}{|c|c|c|c|c|c|c|c|}
\hline $\begin{array}{l}\mathrm{EX} \\
\mathrm{P} \\
\mathrm{NO}\end{array}$ & $\begin{array}{l}\text { SPEE } \\
\mathrm{D} \\
{[\mathrm{m} / \mathrm{min}}\end{array}$ & $\begin{array}{c}\text { FEED } \\
{[\mathrm{mm} / \mathrm{rev}}\end{array}$ & $\begin{array}{l}\mathrm{DO} \\
\mathrm{C} \\
{[\mathrm{mm}}\end{array}$ & $\begin{array}{r}\text { HARDNES } \\
\mathrm{S}[\mathrm{HRC}]\end{array}$ & $\begin{array}{c}\text { Tool } \\
\text { Wear(uncoated } \\
\text { ) }[\mathrm{mm}]\end{array}$ & $\begin{array}{c}\text { Tool } \\
\text { Wear(coated } \\
{[\mathrm{mm}]}\end{array}$ & $\begin{array}{c}\text { Tool } \\
\text { Wear(ceramic } \\
\\
{[\mathrm{mm}]}\end{array}$ \\
\hline 1 & 50 & 0.05 & 0.15 & 51 & 0.245 & 0.19 & 0.129 \\
\hline 2 & 50 & 0.075 & 0.2 & 53 & 0.185 & 0.175 & 0.149 \\
\hline 3 & 50 & 0.1 & 0.25 & 55 & 0.2 & 0.16 & 0.14 \\
\hline 4 & 65 & 0.05 & 0.2 & 55 & 0.2 & 0.19 & 0.19 \\
\hline 5 & 65 & 0.075 & 0.25 & 51 & 0.2 & 0.145 & 0.118 \\
\hline 6 & 65 & 0.1 & 0.15 & 53 & 0.22 & 0.14 & 0.116 \\
\hline 7 & 80 & 0.05 & 0.25 & 53 & 0.21 & 0.19 & 0.193 \\
\hline 8 & 80 & 0.075 & 0.15 & 55 & 0.175 & 0.17 & 0.122 \\
\hline 9 & 80 & 0.1 & 0.2 & 51 & 0.2 & 0.14 & 0.111 \\
\hline
\end{tabular}

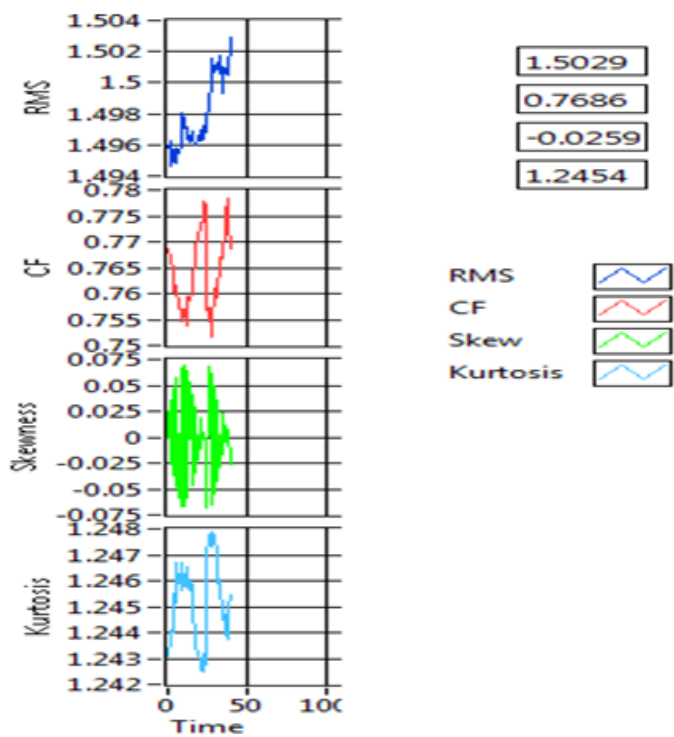

Fig.1 Vibration Signal Captured in Turning

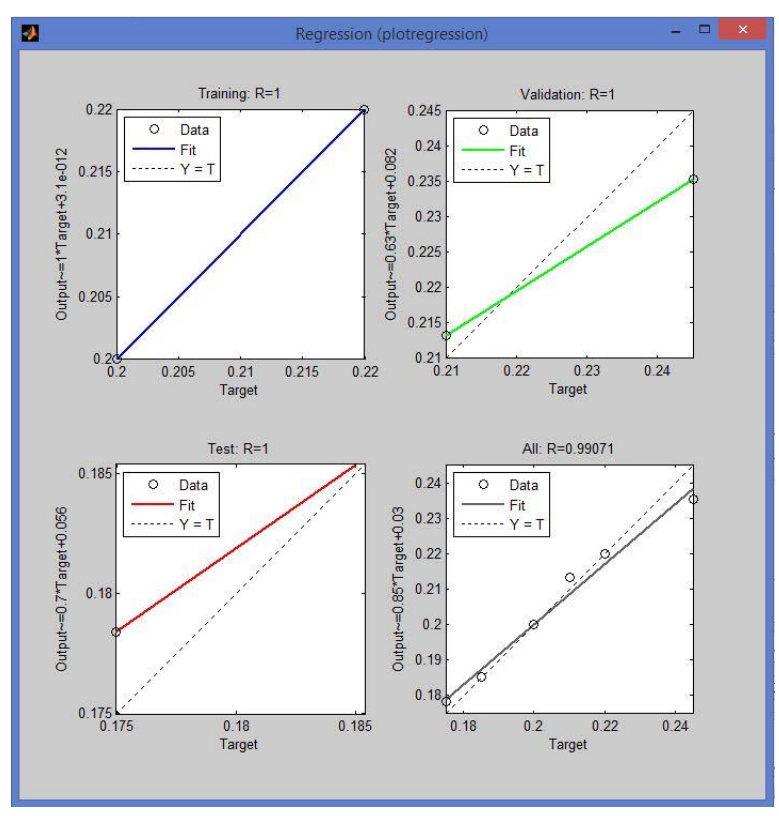

Fig.2 Performance graph for vibration signals (uncoated)

\subsection{Analysis of variance (ANOVA)}

ANOVA examines the null proposition that the population means of every level are equal, versus the alternate hypothesis that minimum one of the level means are not equal. This is obtained by splitting the overall changeability of grey relational grades. It is stately by the sum 
of squared deviations from the total mean of grey relational grade, into contributions from every turning parameters and errors.

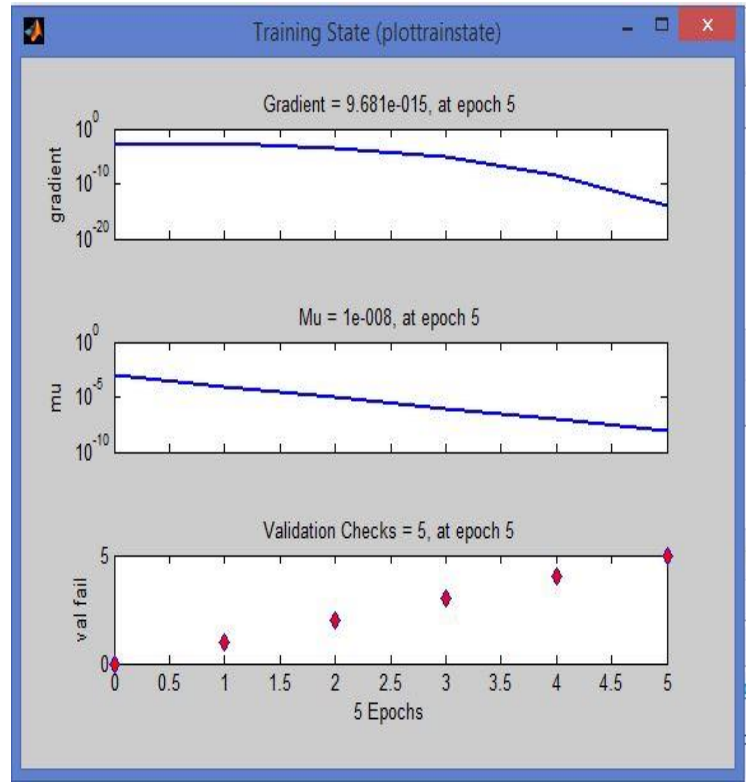

Fig. 3 Training state graph for vibration (uncoated)

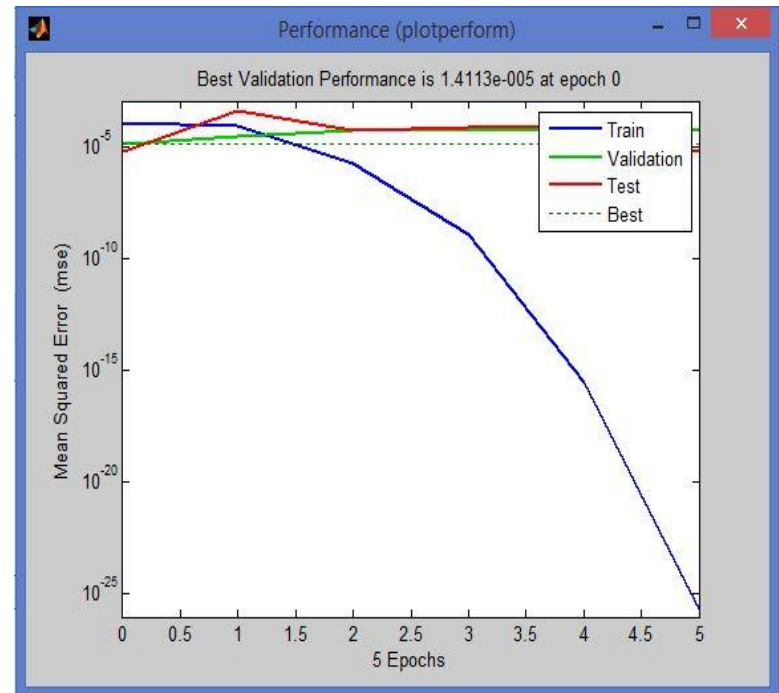

Fig. 5 Performance graph for vibration signals (coated)

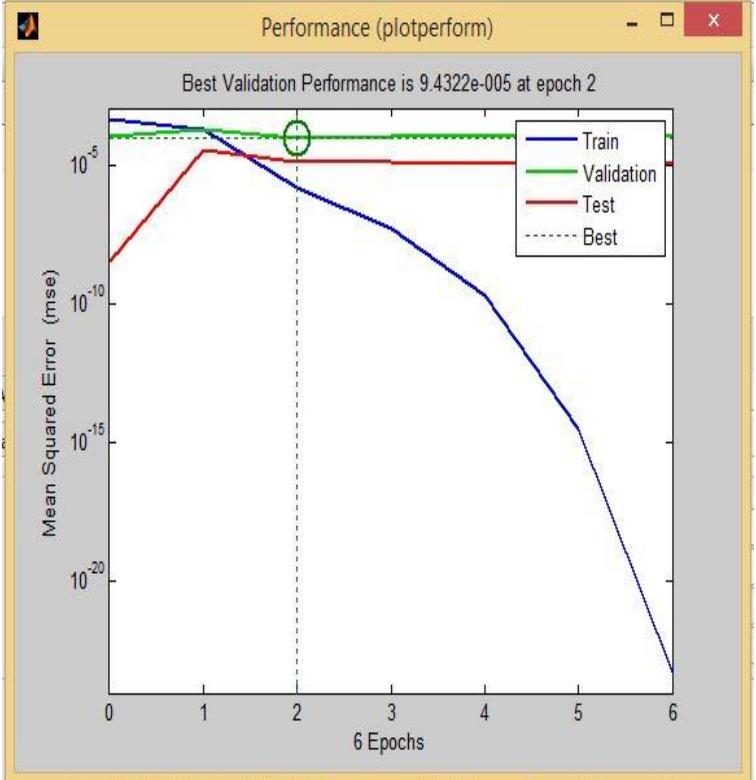

Fig. 4 Regression Graph for vibration signal (uncoated)

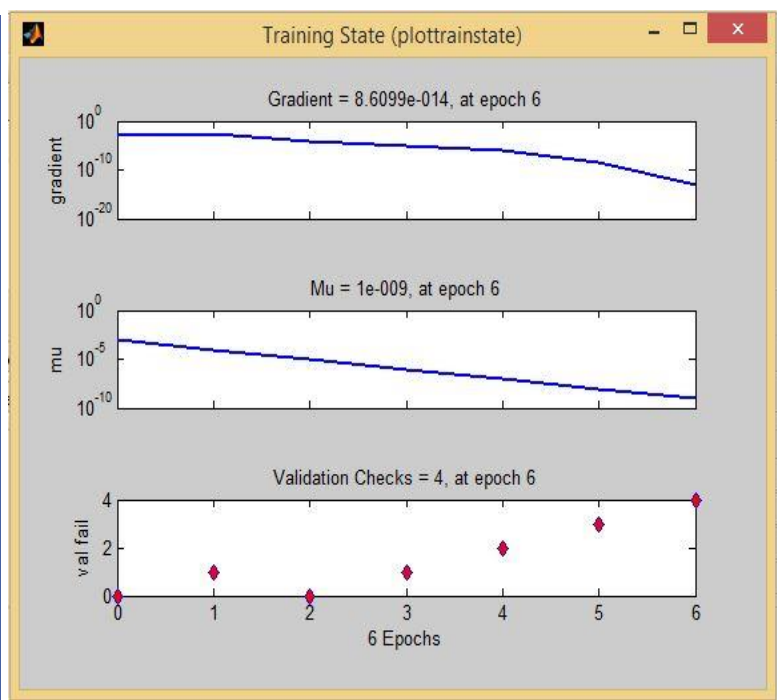

Fig. 6 Training state graph for vibration signal (coated)

In addition, the F-test is used to determine what turning factors have a key effect on the output responses. Commonly, the change of turning parameter has main effect on the output response when the F-value is higher. Fig. 13 shows sequence of percentage contribution of ach feature. Also in ANOVA, AD is found to be the utmost manipulating feature of tool wear. For all three tools, AD is the most dominant feature even after comparing with GRA. 


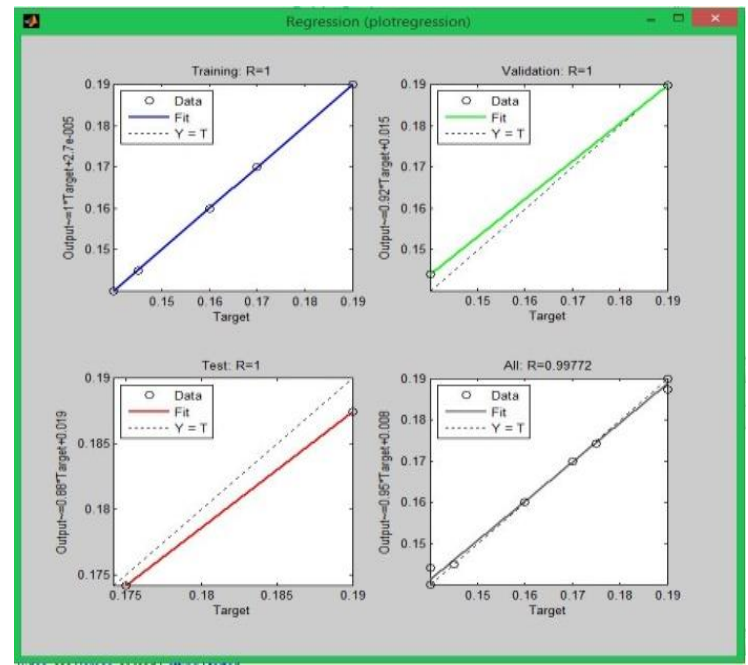

Fig. 7 Regression Graph for vibration signal (coated)

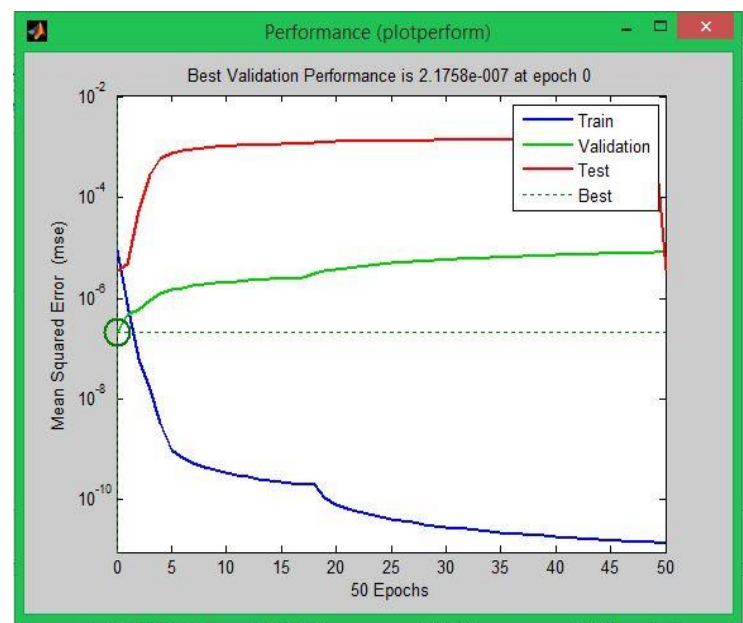

Fig. 8 Performance graph for vibration signals (ceramic)

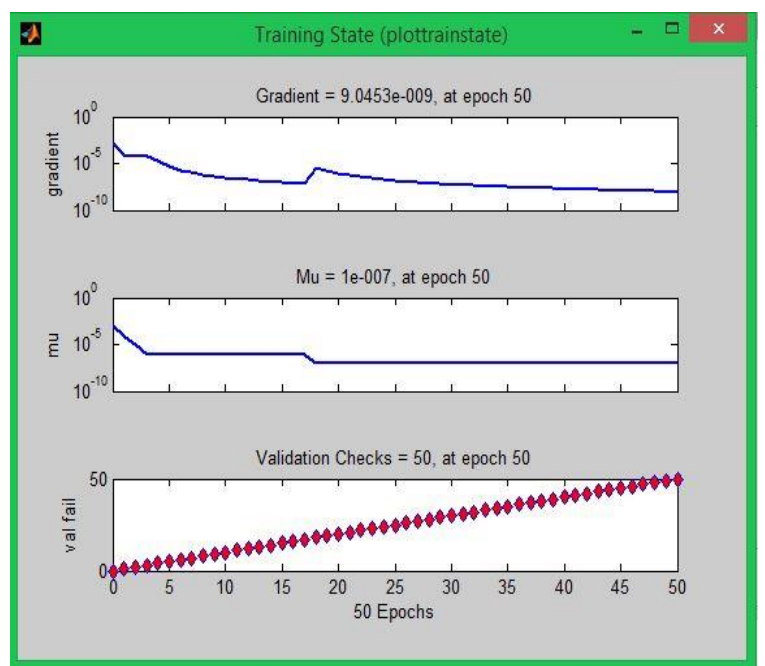

Fig. 9 Training state graph for vibration signal (ceramic)

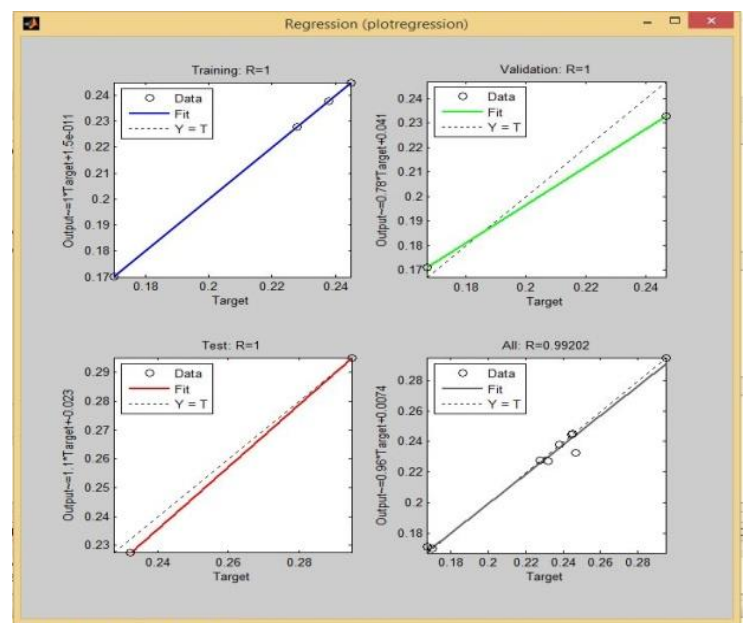

Fig.10 Regression Graph for vibration signals (ceramic)

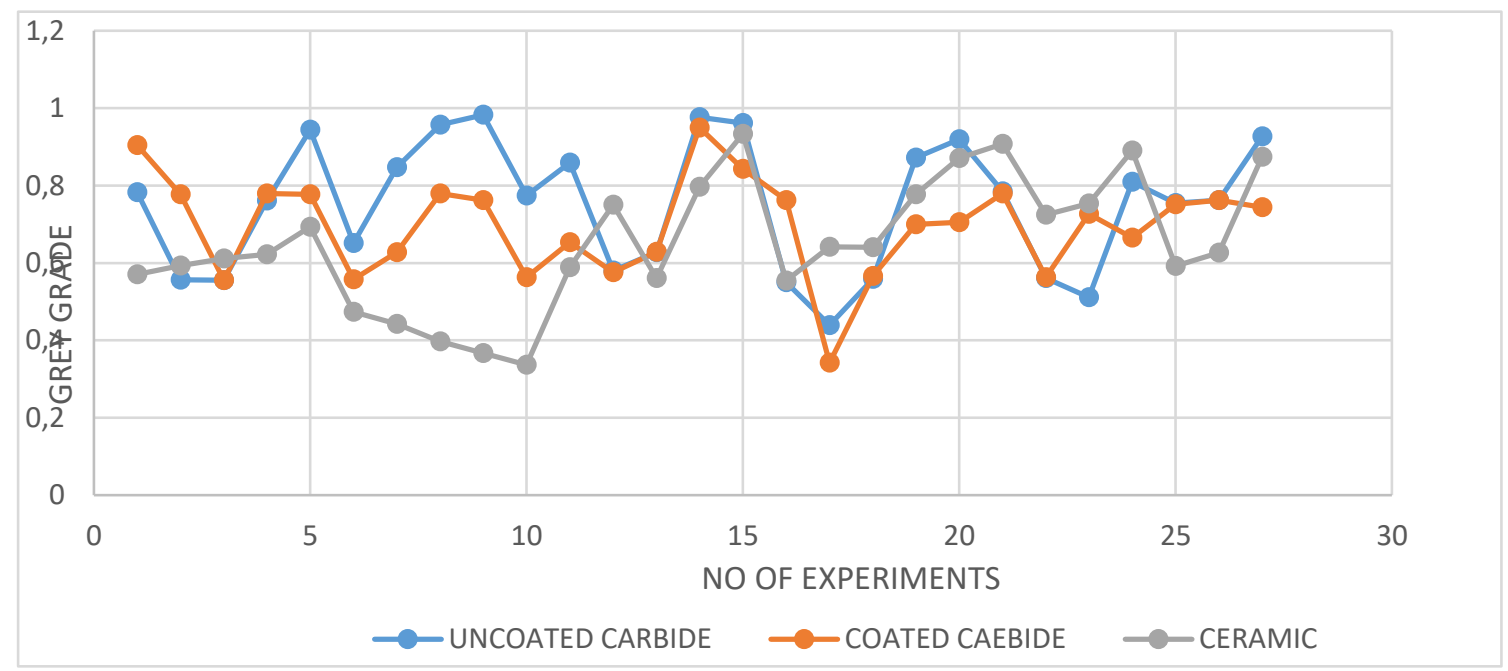

Fig.11 Grey relational grades of experimental runs for Vibration Signals 


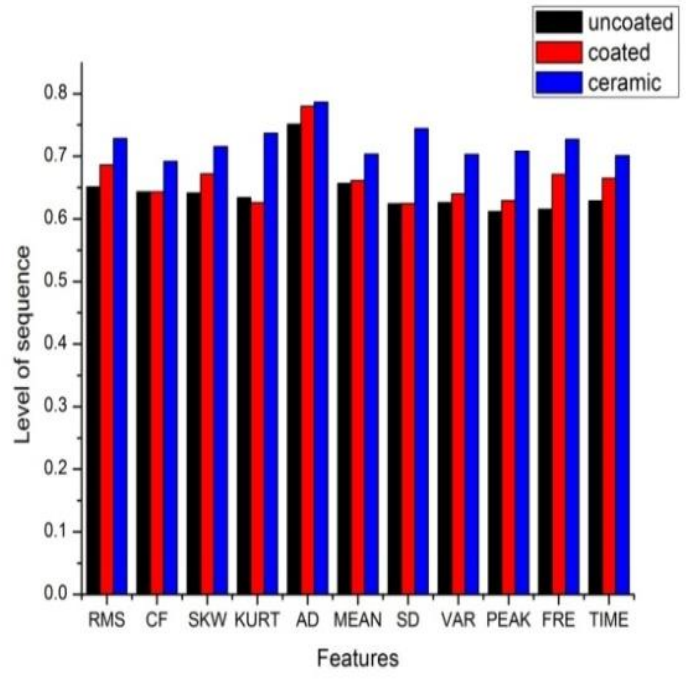

Fig 12. Level of sequence of features

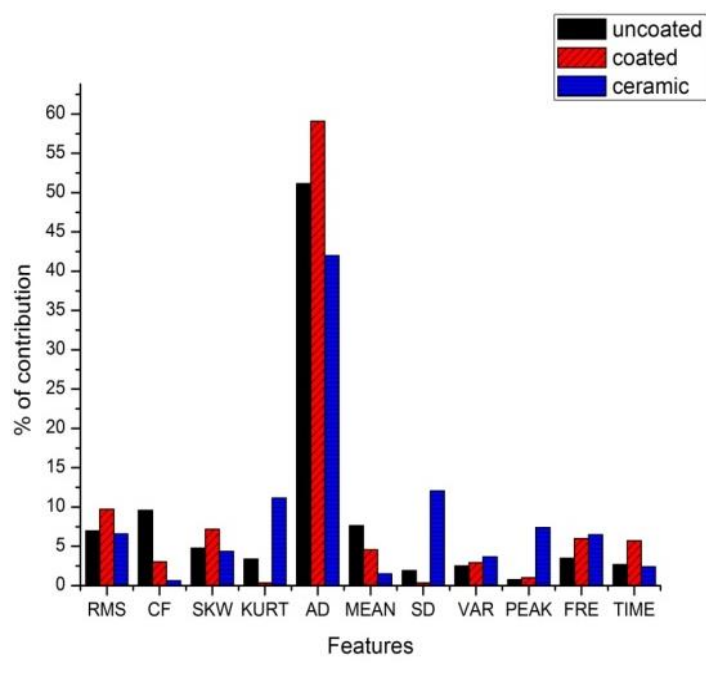

Fig 13. Percentage contribution of features

\section{CONCLUSIONS}

From the present investigation it can be concluded that

$>$ Using both the methods Taguchi and GRA dominant features are observed to find the tool wear in TCM.

$>$ Various Features are assessed from the LAB VIEW and MAT LAB software.

$>$ In MATLAB, a neural network technique is developed to train the remaining features in order to get the relation between tool wear and the dominant features, around $98 \%$ accuracy is observed.

$>$ Tool wear is calculated by Simulating Neural Network, dominant features considered as input data from L27 Taguchi orthogonal array.

$>$ The Simulated data is analyzed by Grey relational method and attained grey grade, which is used to observe the dominant feature for the TCM.

$>$ Absolute Deviation is found to be the most dominant feature for vibration signal.

$>$ ANOVA analysis is accepted for the simulated data and grey codes, recognized that the same feature is obtained for Vibration signal.

\section{REFERENCES}

[1] Ezugwu, E. O. "Key improvements in the machining of difficult to cut aerospace superalloys“, International Journal of Machine Tools and Manufacture 45 (12-13), pp. 1353 - 1367, 2005. DOI: 10.1016/j.ijmachtools.2005.02.003

[2] Olovsjo, S., Nyborg, L. "Influence of micro structure on wear behavior of uncoated WC tools in turning of Alloy718 and Waspalloy“", Wear 282-283, pp. 12 - 21, 2012. DOI: 10.1016/j.wear.2012.01.004

[3] Xiaozhi, C., Beizhi, L. "AE method for tool condition monitoring based on wavelet analysis“, International Journal of Advanced Manufacturing Technology 33 (9), pp. 968 - 976, 2007. DOI: 10.1007/s00170-006-0523-5

[4] Scheffer, C., Kratz, H., Heyns, S., Klocke, F. "Develpoment of tool wear monitoring system for hard turning“, International Journal of Machine Tools and Manufacture 43 (10), pp. 973 - 985, 2003. DOI: 10.1016/S0890-6955(03)00110-X

[5] Kurada, S., Bradley, C. "A review of machine vision sensors for tool condition monitoring", Computers in Industry 34 (1), pp. 55 - 72, 1997. DOI: 10.1016/S01663615(96)00075-9 
[6] Kakade, S., Vijayaraghavan, L., Krishnamurthy, R. "Monitoring of tool status using intelligent acoustic emission sensing and decision based neural network", IEEE, pp. 25 29, 1995. DOI: 10.1109/IACC.1995.465873

[7] Lalta, P., Rahul, K. "Study on Breaking Load of Single Lap Joint Using Hybrid Joining Techniques for Alloy Steel AISI 4140 and Mild Steel: Taguchi and Neural Network Approach“, Strojnícky časopis - Journal of Mechanical Engineering 68 (1), pp. 51 - 60, 2018. DOI: $10.2478 /$ scjme-2018-0005

[8] Milesich, T., Danko, J., Bucha, J. "Neural Networks - A Way to Increase the Fuel Efficiency of Vehicles“, Strojnícky časopis - Journal of Mechanical Engineering 68 (1), pp. 81 - 88, 2018. DOI: $10.2478 /$ scjme-2018-0008

[9] Siddhpura, M., Siddhpura, A., Bhave, S. "Vibration as a parameter for monitoring the health of precision machine tools", In: Conference, International conference on frontiers in design and manufacturing engineering, Coimbatore (India). Macmillan, India, 2008.

[10] Dan, L., Mathew, J. "Tool wear and failure monitoring techniques for turning - a review", International Journal of Machine Tools and Manufacture 30 (4), pp. 579 - 598, 1990. DOI: $10.1016 / 0890-6955(90) 90009-8$

[11] Rao, S.B. "Tool wear monitoring through the dynamics of stable turning", J Eng Ind 108 (3), pp. 183 - 190, 1986. DOI: $10.1115 / 1.3187062$

[12] Weller, E. J., Schrier, H. M., Weichbrodt, B. "What sound can be expected from worn tool?“", J Eng Ind 91(3), pp. 525 - 534, 1969. DOI: 10.1115/1.3591621

[13] Del Taglia, A., Portunato, S., Toni, P. "An approach to online measurement of tool wear by spectrum analysis“, In: Proc 17th international MTDR conference 7, pp. $141-148$, 1976. DOI: $10.1007 / 978-1-349-81484-8 \_17$

[14] Pandit, S.M., Kashou, S. “A data dependent system strategy of on-line tool wear sensing“, J Eng Ind 104 (3), pp. 217 - 223, 1982. DOI: 10.1115/1.3185822

[15] Pandit, S. M., Kashou, S. "Variation in friction coefficient with tool wear", Wear 84 (1), pp. 65 - 79, 1983. DOI: 10.1016/0043-1648(83)90119-9

[16] Jiang, C. Y., Zhang, Y. Z., Xu, H. J. "In-Process Monitoring of Tool Wear Stage by the Frequency Band - Energy Method“, CIRP Annals 36 (1), pp. 45 - 48, 1987. DOI: 10.1016/S0007-8506(07)62550-5

[17] Teti, R., Jemielniak, K., O'Donnell, G., Dornfeld, D. "Advanced monitoring of machining operations“, CIRP Annals 59 (2), pp. 717 - 739, 2010. DOI: 10.1016/j.cirp.2010.05.010

[18] Lu, M. - C., Kannatey - Asibu, E. Jr. "Analysis of Sound Signal Generation Due to Flank Wear in Turning“, J.. Manuf. Sci. Eng. 124 (4), pp. 799 - 808, 2002. DOI: $10.1115 / 1.1511177$

[19] Alonso, F. J., Salgado, D. R. "Analysis of the structure of vibration signals for tool wear detection“, Mechanical Systems and Signal Processing 22 (3), pp. 735 - 748, 2008. DOI: 10.1016/j.ymssp.2007.09.012

[20] Rajesh, V. G., Narayanan Namboothiri, V. N. "Flank wear detection of cutting tool inserts in turning operation: application of nonlinear time series analysis“, Soft Compute 14, pp. 913 - 919, 2010. DOI: 10.1007/s00500-009-0466-5

[21] Ding, F., He, Z. "Cutting tool wear monitoring for reliability analysis using proportional hazards model", International Journal of Advanced Manufacturing Technology 57 (58), pp. 565-574, 2011. DOI: 10.1007/s00170-011-3316-4 